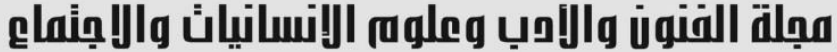

Journal of Arts, Literature, Humanities and Social Sciences www.jalhss.com

\section{التفكير المنتج وعلاقتهُ بمهارات القرن الواحد والعشرين لدى طلبة قسم الرياضيات في كلية التربية}

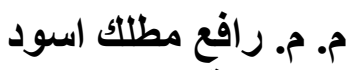

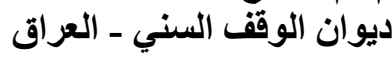

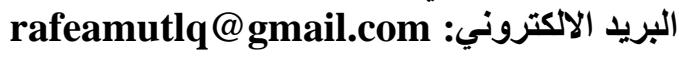

بحثُ حالي يهدف إلى تَعرّف علاقه بين التفكير المنتج و مهارت قرن واحد وعشرين ، ،حيث تكونت عينه بحث من (420) طالب وطالبه بعد استبعاد عدد من طلبه غائبين من كليه تربيه للعلوم صرفه ابن الهيثم،( دراسه صباحيه ومسائيه )،إذ تم سحب تللك عينه على وفق طريقه عشو ائيه مرحليه. حيث استعمل بحث اداتين هما : اختبار التفكير المنتج و مقياس مهارات قرن واحد وعشرين الذي قام باحث ببنائها ،وتكون اختبار تفكير منتج من (37) فقره قام باحث ببنائها اما اداه ثانيه فهو ( مقياس مهارات 21 ) وتكون من (45) فقره تندرج تحته اربعه بدائل، ، ونتَّ تحققً من خصائص سايكو منريه للمقياس و الاختبار من صدق ظاهري، وثنات بطريقه اتساق داخلي ، وبعد جمع معلومات ومعالجتها إحصائيا، نوصل باحث إلى نتائج الآتيه: 1. اظهرت نتائج ان طلبه مرحله رابعه/كليه تربيه يمتلكون مهار ات قرن و واحد و والعشرين. 2. اظهرت نتائج ان طلبه مرحله رابعه/كليه نربيه يمتلكون التفكير المنتج. 3. اظهرت النتائج وجود علاقه داله بين درجات التفكير المنتج و مهار ات قرن واحد و عشرين لدى طلبه. 


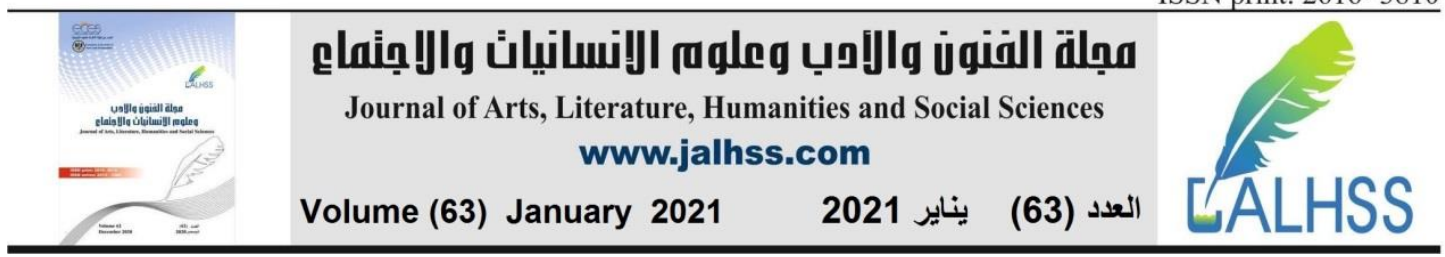

Productive Thinking and its Relationship to the Twenty-First Century Skills among Students of the Mathematics Department in the College of Education

\author{
Assist. Lect. Rafe Mutlak Aswad \\ The Sunni Endowment Office - Iraq \\ Email: rafeamutlq@gmail.com
}

\begin{abstract}
Current research aims to identify a relationship between productive thinking and the skills of the twenty-first century, where a sample consisted of (420) students and students after excluding a number of absent students from the Faculty of Education that was dismissed by the collge of education for pure sience ibn al - haytham (morning and evening study), as that sample was withdrawn According to a random, phased way. Where the research used two tools: the Productive Thinking Test and the Twenty One Century Skills Scale, which a researcher built, and the Productive Thinking Test consisted of (37) paragraphs that a researcher constructed. A second tool is (Skills Scale 21) and it consists of (45) paragraphs that fall under the four Alternatives The psychometric properties of the scale and the test were verified for their apparent validity and validity by means of internal consistency and by Alpha Cronbach, and after collecting information and treating it statistically, a researcher reached the following results:

1.Results showed that fourth-grade / college education students possess twenty-first century skills.

2. Results showed that fourth-stage / college education students possess productive thinking.

3. The results showed a significant correlation between the degrees of productive thinking and twenty-one century skills of the students.
\end{abstract}

Keywords: Productive Thinking, 21st Century Skills, Mathematics, College of Education. 


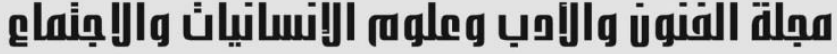

Journal of Arts, Literature, Humanities and Social Sciences www.jalhss.com

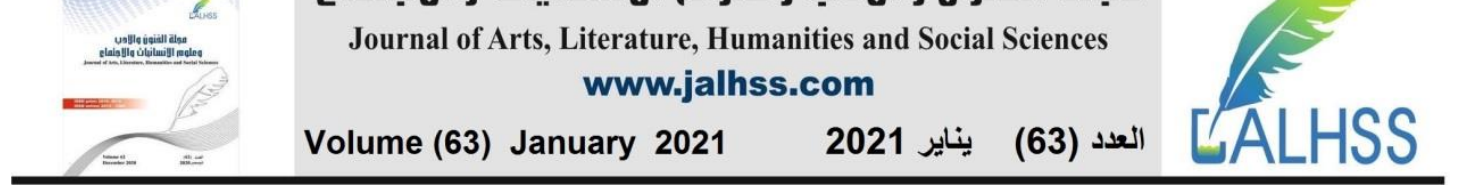

\section{الفصل الاول}

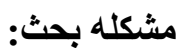

نظر ا للحاجه ماسه إلى مو اهب واهُ ومهار ات جديده في عصر معلومات ولتطوير قدرات متعلمين شخصيه، بحيث

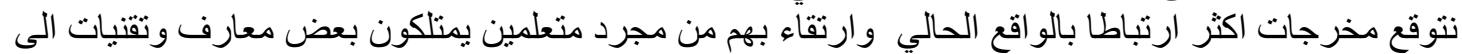

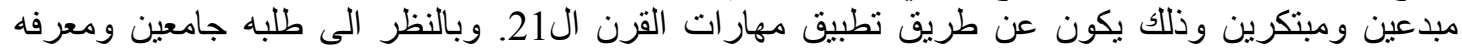

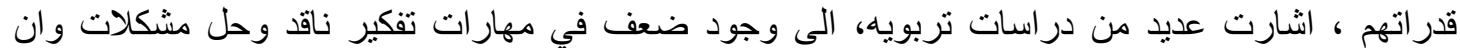

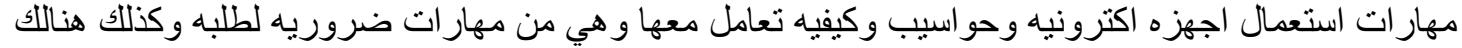

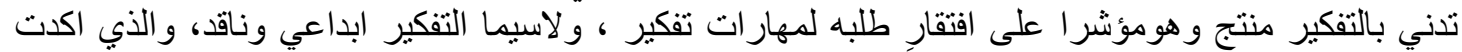

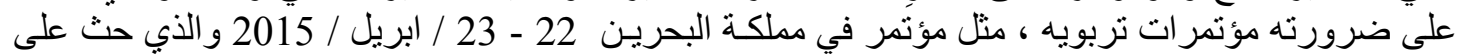

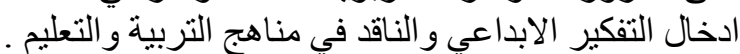

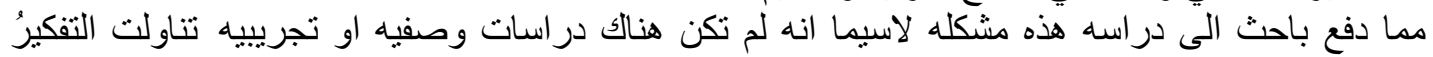

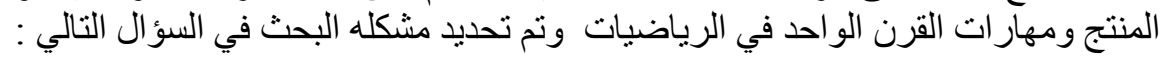

هل هناللك علاقه بين التفكير المنتج و مهار ات قرن واحد و عشرين لدى طلّبه قسم الرياضيات في كليه تربيه؟

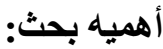

ا همبيه نظريه:

1. هذه در اسه تتمثل من توجهات عالميه التي تنادي بضروره امتلاك متعلمين مهار ات قرن 21 و هذا ما تمسه باحث من خلال دراسات وصفيه الذي اطلع عليها ويحاول باحث وقوف على مدى مدى امتلاك عينه بحث في هذه مهار ات.

2. درره در اسـات محليه التي تناولت التفكير المنتج والتي يجب ان بمتلكها طلبه قسم الرياضيات في كليه تربيه. النظريات التطبيقيه :

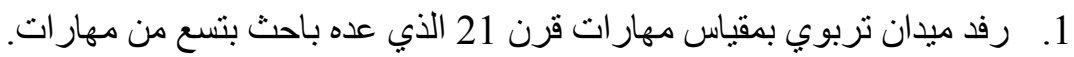

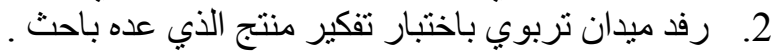

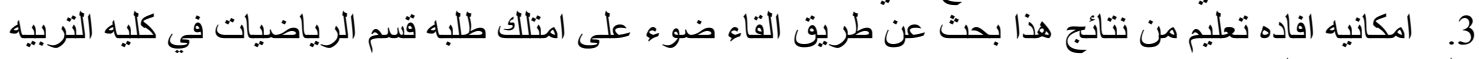

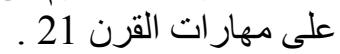
هدفف بحثث: بحثُ حالي إلى تَعرّف العلاقه بين التفكير المنتج و مهار ات قرن و احد و عشرين لدى طلبه قسم الرياضيات في كليه التربيه فرضيات البحث: في كاه

1- لايوجد فرقُ ذو دلاله إحصائيه بين متوسطات لدرجات طلبه مرحله رابعه /كليه التربيه، من عينه البحث في التفكير المنتج.

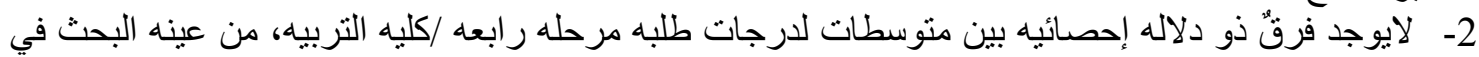
مهار ات القرن الو احد و العشرين. 3- هل توجد علاقه ارتباطيه بين درجات طلبه المرحله الرابعهداكليه التربيه في اختبار التفكير المنتج ودرجاتهم

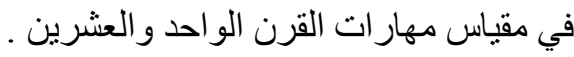
حدود البحث: معث: 1- طلبه مرحله رابعه / كليه تربيه للعلوم الصرفه ابن الهيثم/جامعة بغداد.

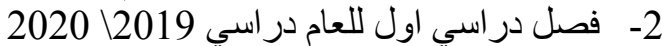
تحديد المصطلحات:

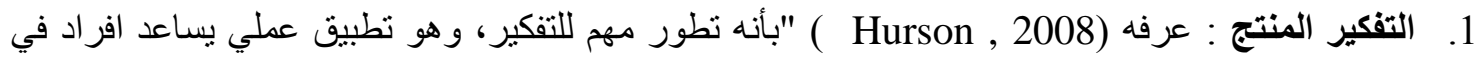

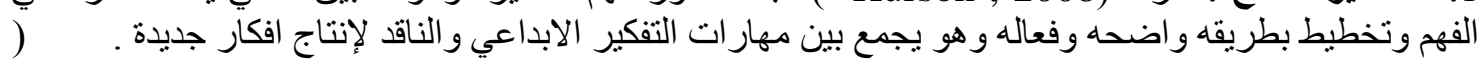

( Hurson ,2008 : p 45

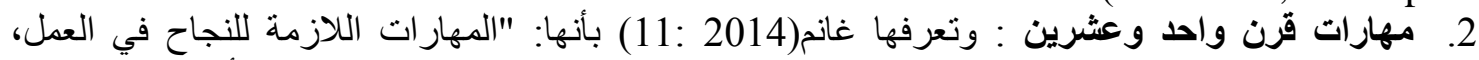

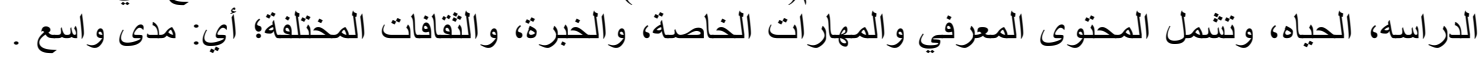




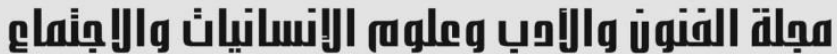 \\ Journal of Arts, Literature, Humanities and Social Sciences www.jalhss.com

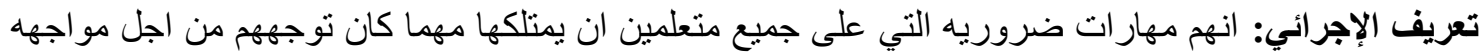

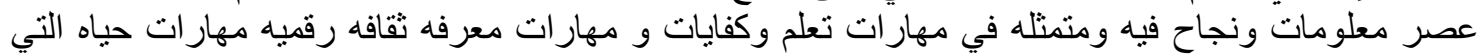

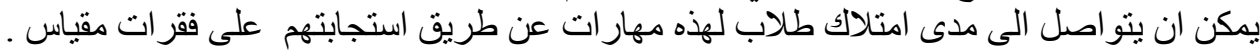

\section{الاطار النظري ودراستات سـابقة}

المحور الاول: الاطار النظري

Productive Thinking اولا : التفكير المنتج: الاطنج النظئ

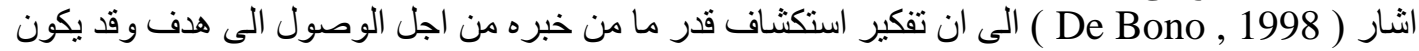

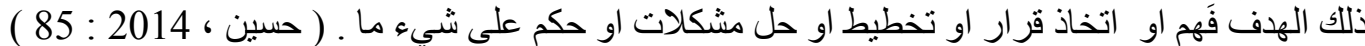

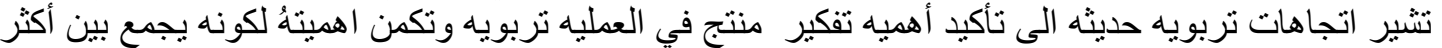

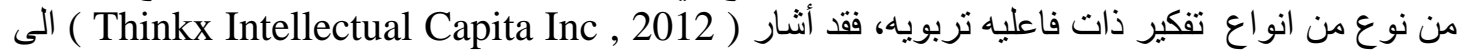

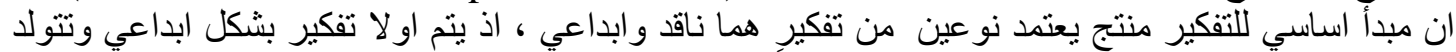

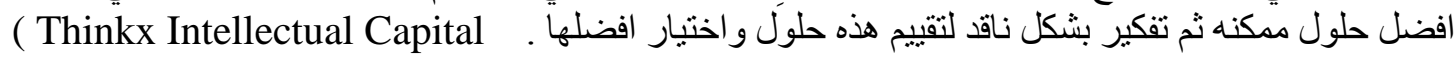
Inc. , 2012:2

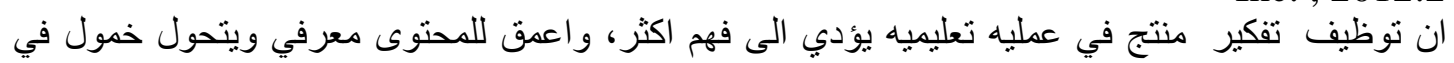

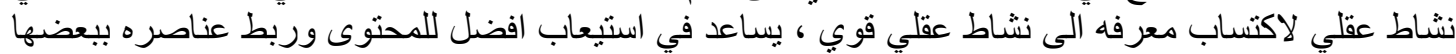

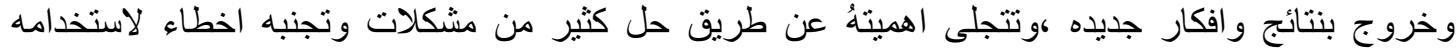

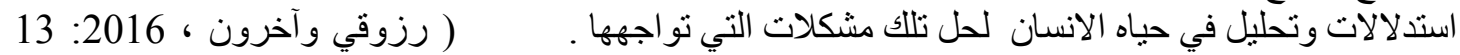

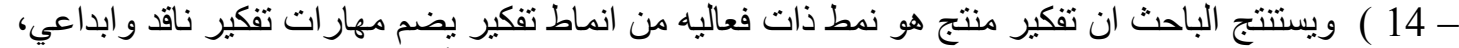

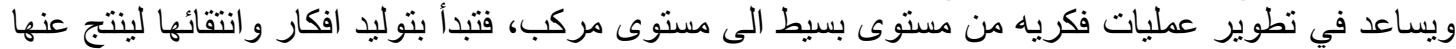

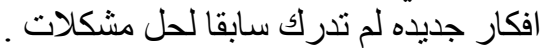

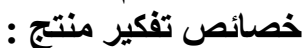

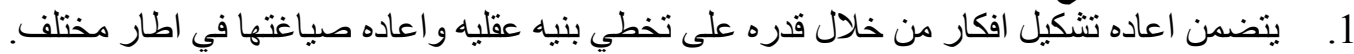

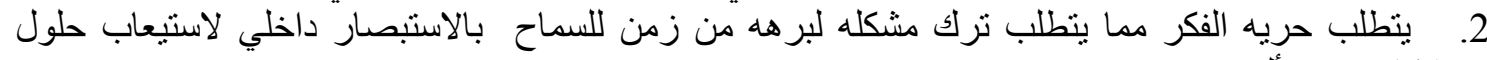
و افكار غير مألوفه .

3. يشتمل على عناصر تفكير تشعبي وتفكير تقاربي، ووضع حلول في مجموعات واعتماد معايير لاختيار حل مشكله .

4. هو تفكير منظم يبنى على مجمو عه من مبادئ ، ويمتاز بالحرص في الاستنتاج بعيدا عن ذاتيه.

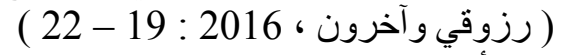

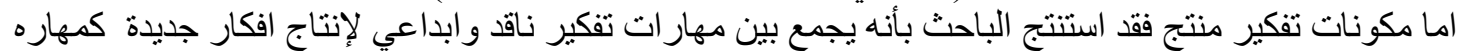

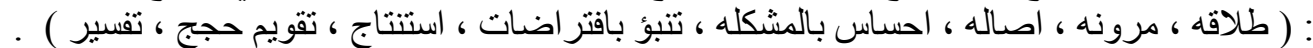

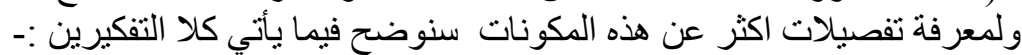

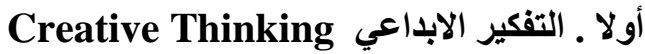
يعد التفكير الابداعي نشاط عقلي مركب التباعب توجهه رغبة هادفة وقوية للبحث عن حلول او التوصل الى نتائج لم تكن

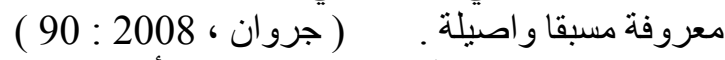

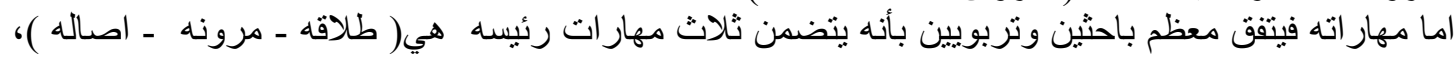

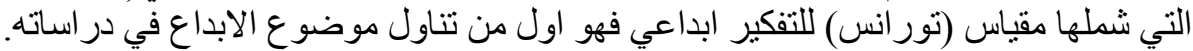

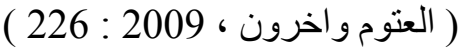

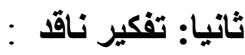

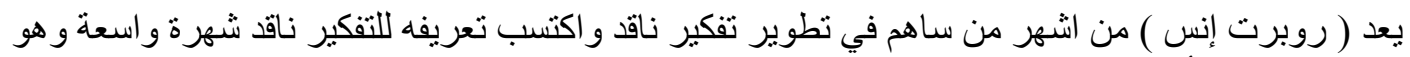

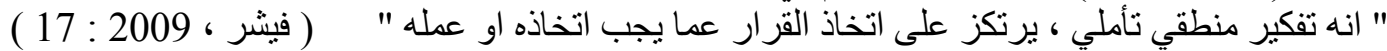

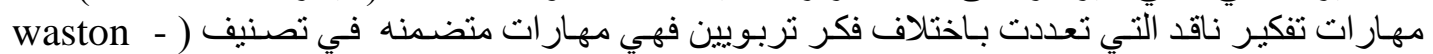
( Glasser 


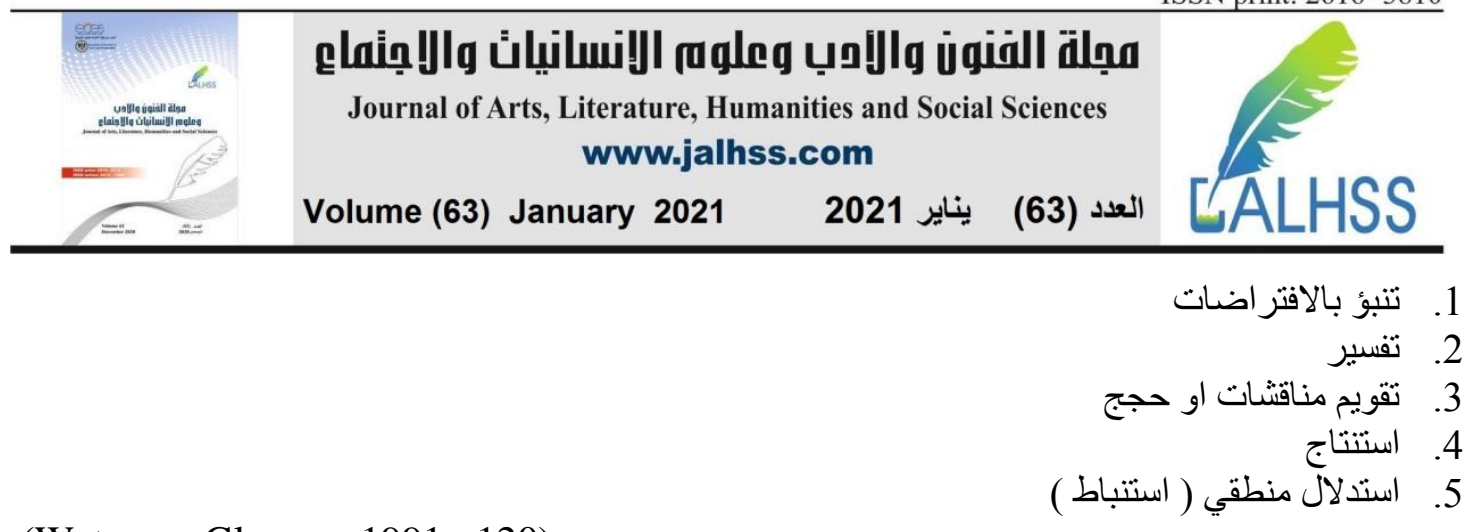

(Watson - Glasser , $1991: 120$ )

ثانيا : مهارات القرن الحادي والعشرين

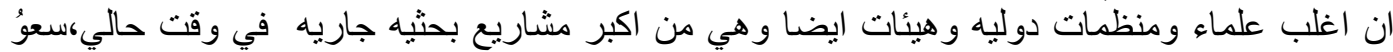

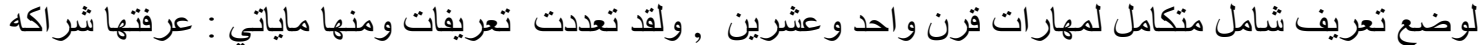

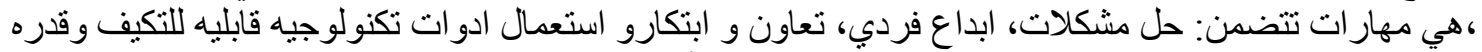

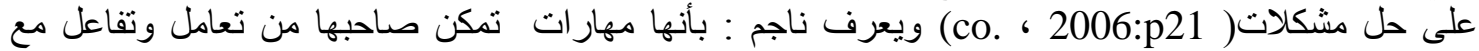

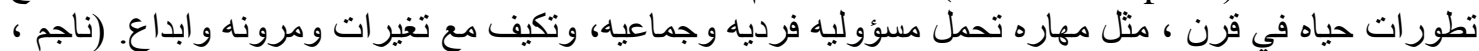

هنالك مبررات الهتمام بمهارات قرن واحد وعشرين ومنها:

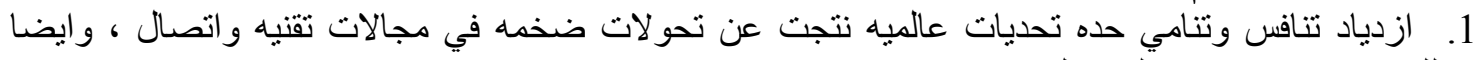

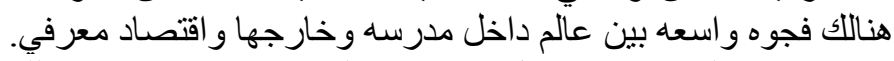

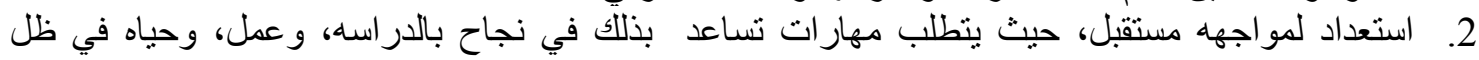

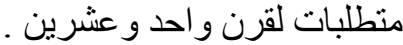

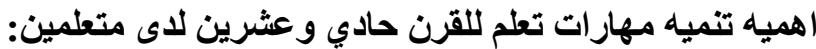

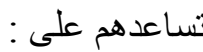
1. تفاعل وتعامل بإيجابيه مع مجتمع ،وتكسبهر ثقه بالنفس، وقدره على إئى اتخاذ القرار.

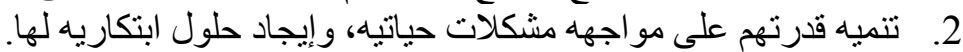

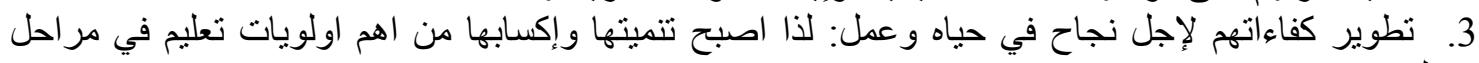
مختلفه.

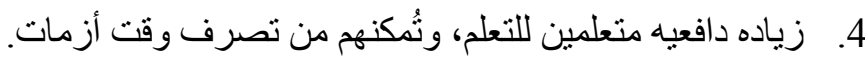

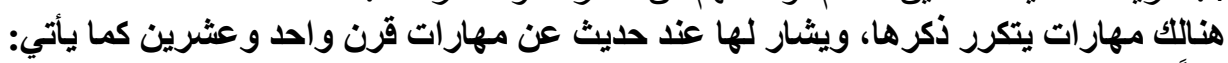
اولاً: مهارات التعلم والابتكار تتلخص مهار ات تعلم و ابتكار بما يلي: 1. 1 تفكير ناقد وحل مشكلات.

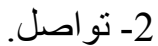

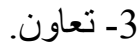

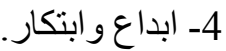
ثثانيا: مهارات تكنولوجيا معلومات واعلام:

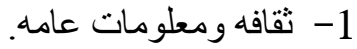
2- 2 نقافه اعلاميه. 3- نقافة تكنولوجيا معلومات و واتصالات. ثالثاً: مهارات حياتيه ووظيفيه ومن هذه مهار ات ما يأتي: 1- مرونه وقدره على تكيف. 2- - مبادره وتوجيه ذاتي. 3- مهار ات اجتماعيه وثقافيه. 4- انتاجيه ومساءله. 


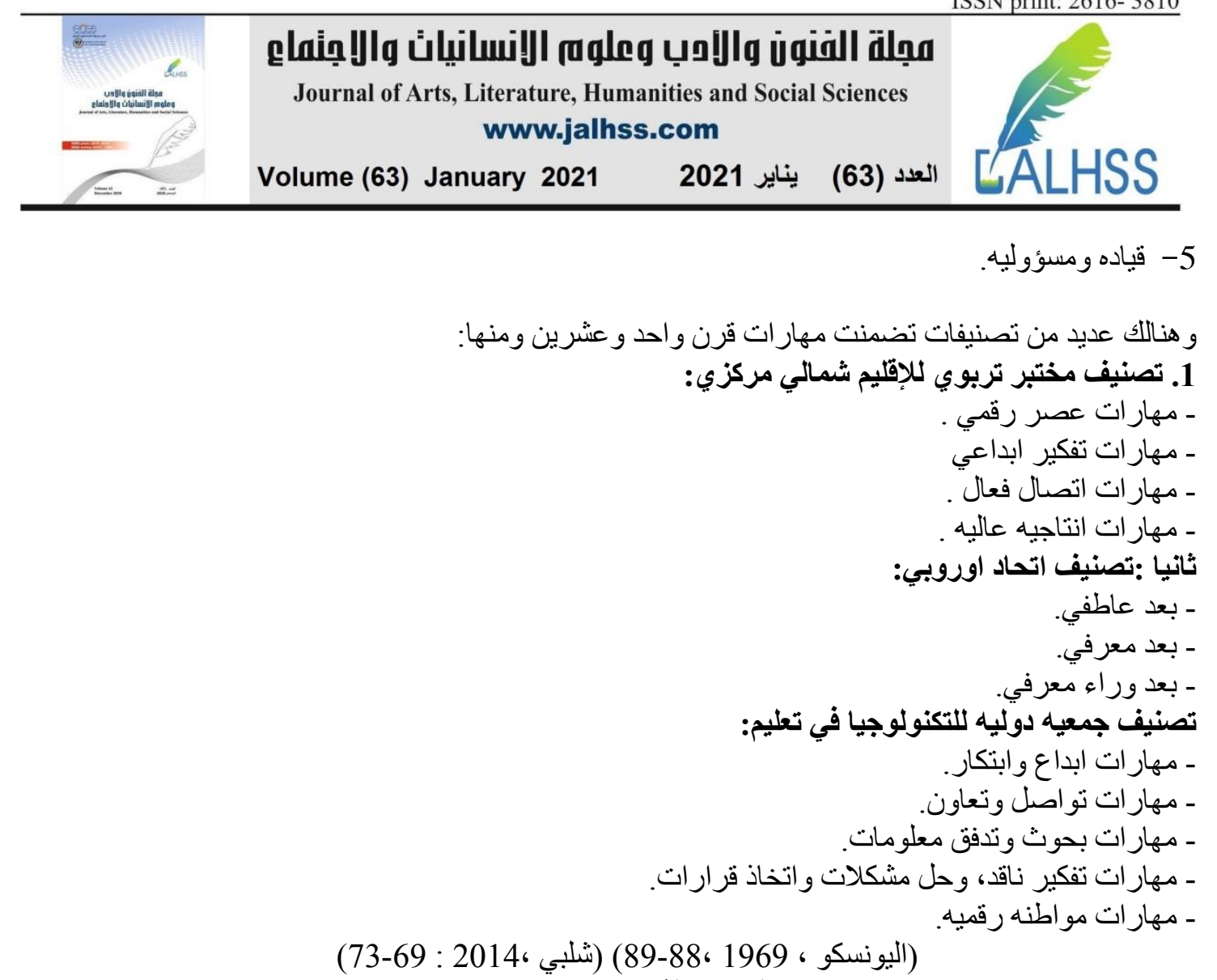

المحور الثاني :دراسات سابقه

\begin{tabular}{|c|c|c|c|c|c|c|c|}
\hline 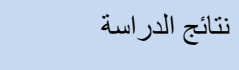 & 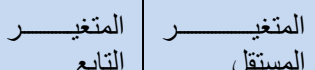 & الإحصـــائسة & 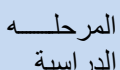 & منهج & هدف الدر اسه & الباحث & ت \\
\hline 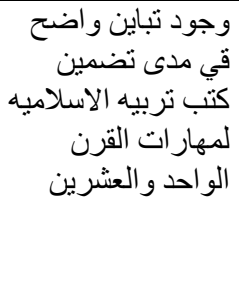 & 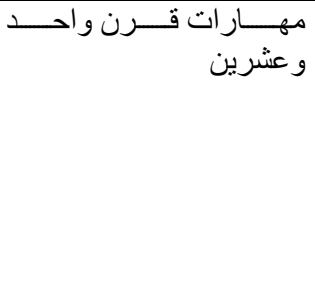 & 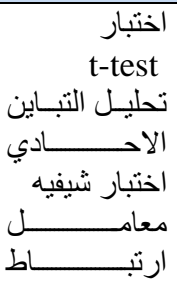 & 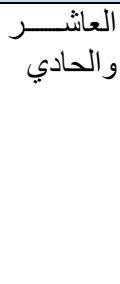 & وصلبه & التراء كتب تربيه & 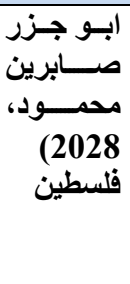 & 1 \\
\hline 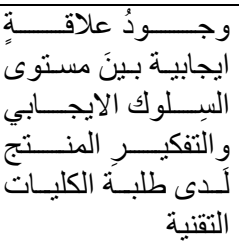 & 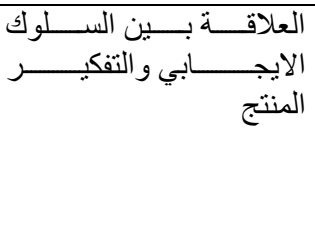 & & 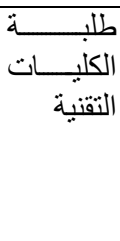 & التوصليليـي & 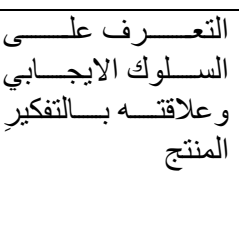 & 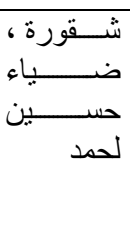 & .2 \\
\hline
\end{tabular}




\begin{tabular}{|c|c|c|c|c|}
\hline Las & 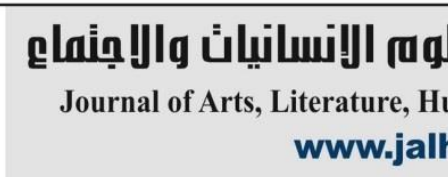 & $\begin{array}{l}\text { tillg Ü } \\
\text { ties and Socia } \\
\text { =om }\end{array}$ & $\begin{array}{l}\text { âll älna } \\
\text { Sciences }\end{array}$ & \\
\hline$==$ & Volume (63) January 2021 & يناير 2021 & العدد (63) & \\
\hline
\end{tabular}

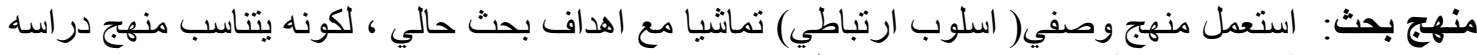

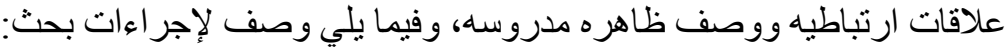

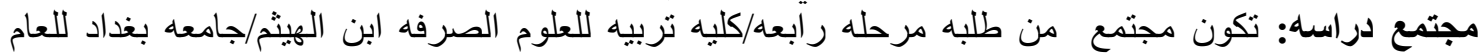

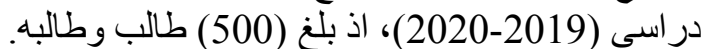
عينة بحث: تألفت عينه بحث من (420) طالب وطالبه من كليه تربيه للعلوم الصرفه البه ابن الهيثم/جامعه بغداد.در اسه

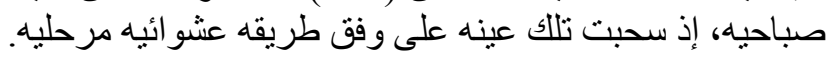

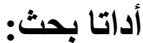
اولا: اختبار التفكير المنتج

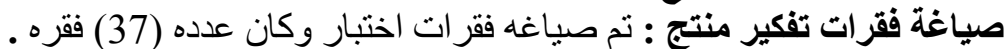

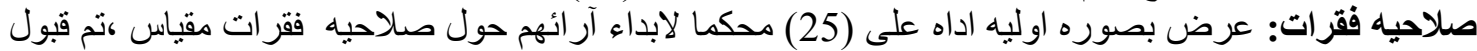

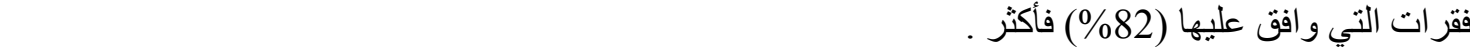

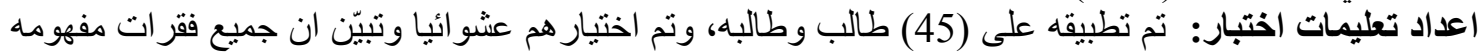

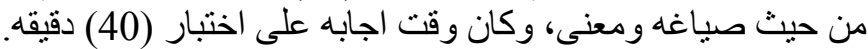

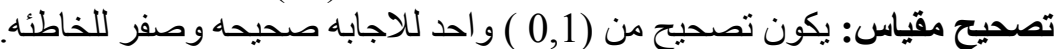

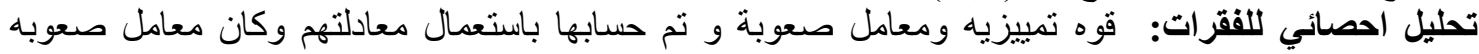

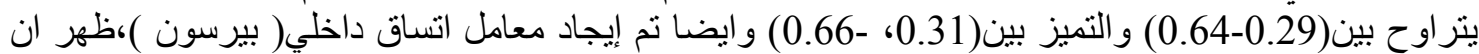

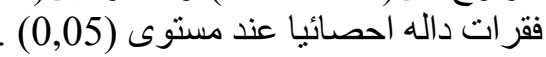
خصائص سايكومتريه للتفكير:

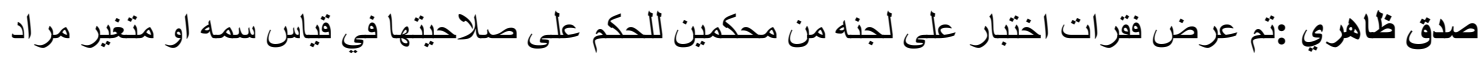

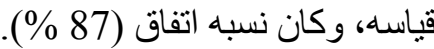

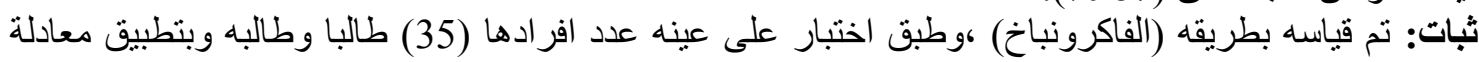

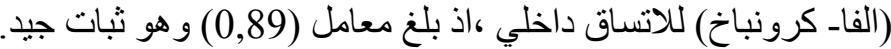

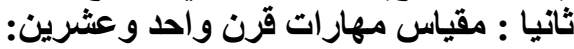

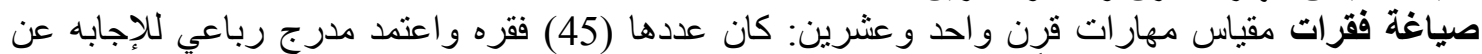

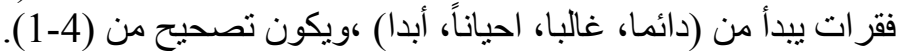

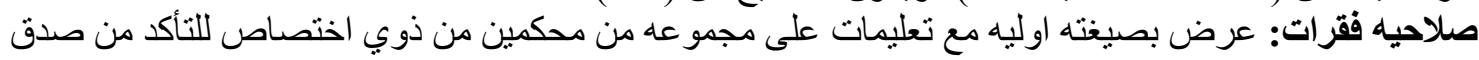

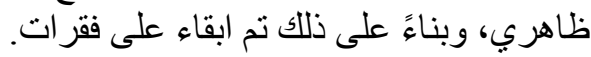
تجربه استطلاعيه: تم تطبيق مقياس مهارات قرئ قرن على على عينه عشوائيه بلغت (50) طالبا، بو اقع (25) طالب،

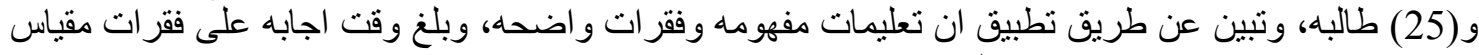

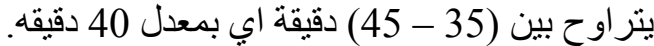

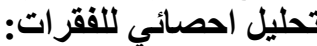

أولا: القوة التمييزيه:طبق مقياس بصورته اوليه على (400) طالب اختيروا بطريقه عشو ائيه.

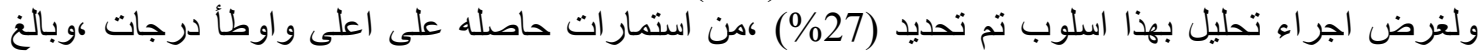

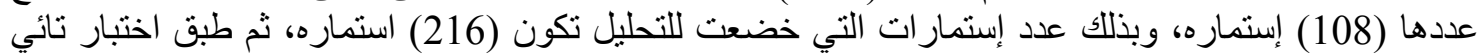

(T-Test)

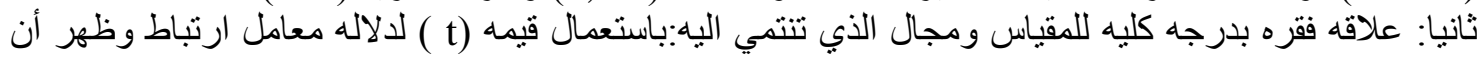

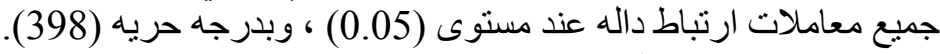

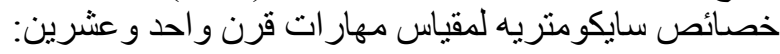

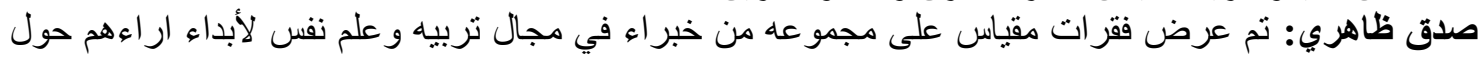

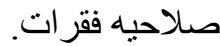
الثبات: تم ايجاد ثبات مقياس بطريقه اتساق داخلي، اذ طبق على عينه بلغ (60) فردا ،وبتطبيق معادله (الفاكرونباخ) ،اذ بلغ معامل ثبات بهذه طريقه (0,86). 


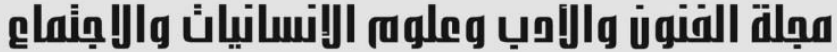

Journal of Arts, Literature, Humanities and Social Sciences

\section{www.jalhss.com}

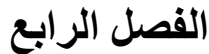

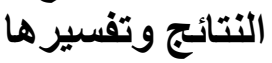

هدف اول: تعرف على تفكير منتج لدى طلبه مرحل ر ابعه/ قسم علوم حباهـ كلبه تربيه.

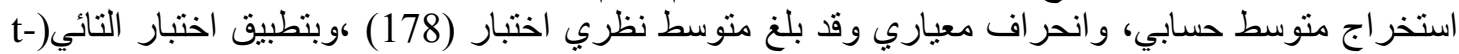

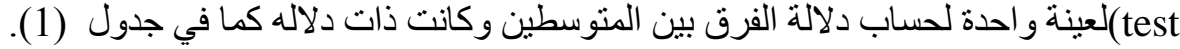

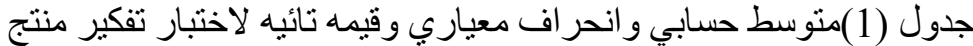

Table (1) arithmetic mean, standard deviation, and a tee value for a test of productive thinking

\begin{tabular}{|c|c|c|l|c|c|c|c|}
\hline $\begin{array}{c}\text { Significanc } \\
\text { e level0.05 }\end{array}$ & $\begin{array}{c}\text { Calculated } \\
\text { TvalueTabular } \\
\text { value }\end{array}$ & $\begin{array}{c}\text { Calculated T } \\
\text { value }\end{array}$ & Df & $\begin{array}{c}\text { Hypothesis } \\
\text { average }\end{array}$ & $\begin{array}{c}\text { standard } \\
\text { deviation }\end{array}$ & $\begin{array}{c}\text { Arithmetic } \\
\text { mean }\end{array}$ & the sample \\
\hline sign & 1.96 & 35.15 & 209 & 178 & 17.3 & 218.7 & 210 \\
\hline
\end{tabular}

هدف ثاني: تعرف على مهار ات قرن و احد و عشرين لدى طلبه مرحله رابعه / قسم علوم حياه/كليه تربيه.

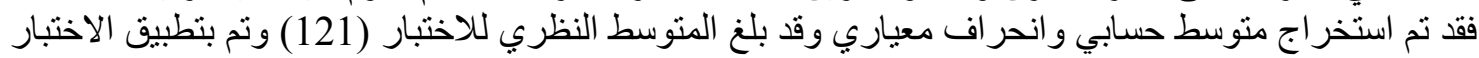

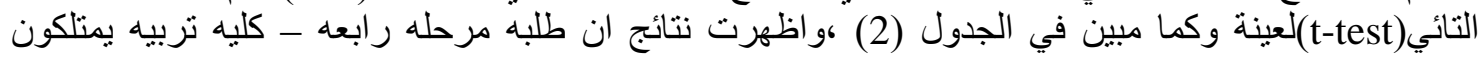
جدول (2) منوسط حسابي وقيمه تائيه لمهار ات قرن حادي و عشرين مهار ات قرن و احد و عشرين.

Table (2) arithmetic mean and missing values for twenty-first century skills

\begin{tabular}{|r|r|l|r|l|l|l|r|}
\hline $\begin{array}{l}\text { Significance } \\
\text { level0.05 }\end{array}$ & $\begin{array}{l}\text { Calculated } \\
\text { TvalueTabular } \\
\text { value }\end{array}$ & $\begin{array}{l}\text { Calculated T } \\
\text { value }\end{array}$ & Df & $\begin{array}{l}\text { Hypothesis } \\
\text { average }\end{array}$ & $\begin{array}{l}\text { standard } \\
\text { deviation }\end{array}$ & $\begin{array}{l}\text { Arithmetic } \\
\text { mean }\end{array}$ & the sample \\
\hline sign & 1.96 & 39.35 & 209 & 121 & 14,9 & 158.3 & 210 \\
\hline
\end{tabular}

هدف ثالث: علاقه بين تفكير منتج ومهار ات قرن واحد و عشرين لدى طلبه مرحله رابعه / كليه تربيه.

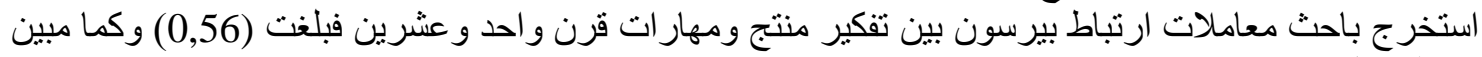

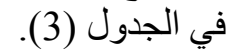
جدول (3) علاقه بين تفكير منتج و مهارات قرن واحد وعشرين لاى طلبه مرحله رابعه / كليه تربيه. 


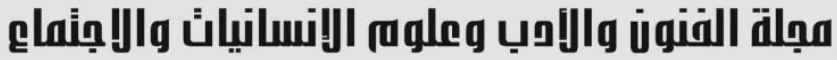 \\ Journal of Arts, Literature, Humanities and Social Sciences www.jalhss.com \\ Volume (63) January 2021 \\ يناير 2021

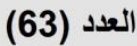

Table (3): A relationship between productive thinking and twenty-one century skills for fourth-stage / college education students.

\begin{tabular}{|c|c|c|c|c|c|}
\hline \multirow{2}{*}{$\begin{array}{l}\text { Significance } \\
\text { level } 0.05\end{array}$} & \multicolumn{2}{|c|}{ The T-test } & \multirow{2}{*}{$\begin{array}{c}\text { Correlation } \\
\text { coefficient } \\
\text { value }\end{array}$} & \multirow{2}{*}{ the sample } & \multirow{2}{*}{ Variables } \\
\hline & $\begin{array}{c}\text { Tabular } \\
\text { value }\end{array}$ & $\begin{array}{c}\text { Calculated } \mathrm{T} \\
\text { value }\end{array}$ & & & \\
\hline \multirow{2}{*}{ Sign } & \multirow{2}{*}{1.96} & \multirow{2}{*}{8,255} & \multirow{2}{*}{0.56} & \multirow{2}{*}{420} & $\begin{array}{c}\text { Twenty-one } \\
\text { century skills }\end{array}$ \\
\hline & & & & & $\begin{array}{c}\text { Tannour } \\
\text { Technology }\end{array}$ \\
\hline
\end{tabular}

اظهرت نتائج وجود علاقه داله بين درجات تفكير منتج و مهار ات قرن واحد و عشرين لدى طلبه؟ الاستنتاجات

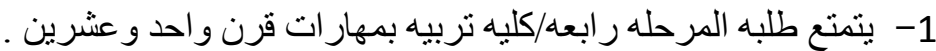

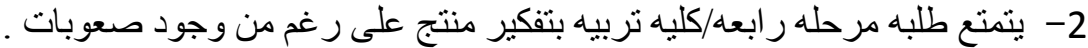
3- 3- التوصيات: 1- افاده من مقياس مهارت قرن 21 واختبار تفكير منتج اللذان اعدهم باحث في بحثه حالي وذلك لتشخيص هذه قدر ات لدى طلبه وشر ائح اخرى من من مجتمع.

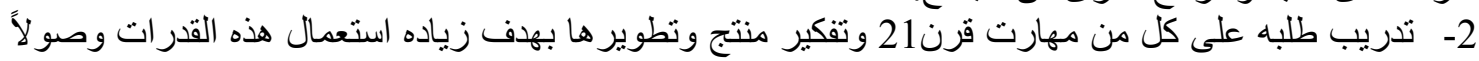
إلى نتائج افضل.

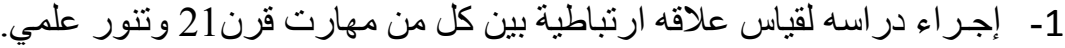

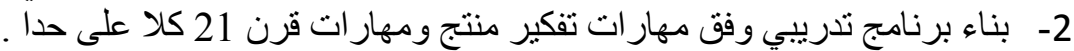

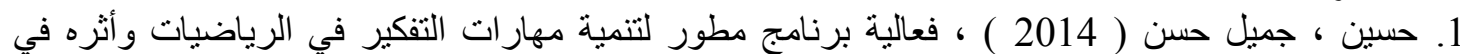

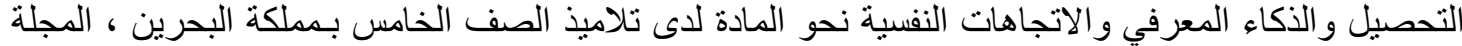

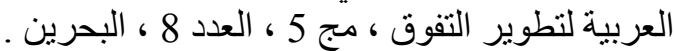
2.

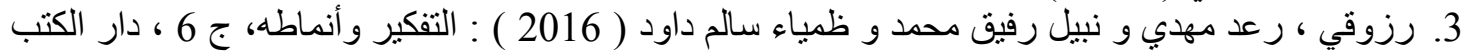

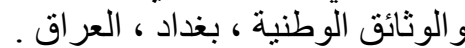
4. فيشر ، آلك فيشر (2009 ) ) : مقدمة في التفكير الناقد ، ط 1 ، دار السيد للنشر ، مؤسسة حمد بن راشد آل

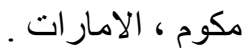




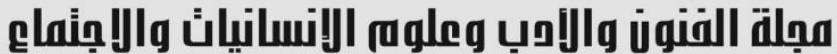

usllitiaiallallas

Journal of Arts, Literature, Humanities and Social Sciences

\section{www.jalhss.com}

\section{Volume (63) January 2021}

العدد (63) يناير 2021

5. شلبي نوال، (2014): اطار مقترح لدمج مهارات القرن الواحد و العشرين في مناج العلوم بالتعليم الاساسي

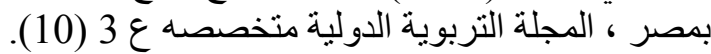

6. الجامعة العربية المفتوحة مؤتمر "تطوير الابداع و التفكير النقدي في التربية والتعليم ، 2015 ، 22 -23 ابريل ، مملكة البحرين .

1. ابو جزر ، صابري محمودي: اثراء كتب الاسلامية الفلسطينية للصفين العاشر والحادي عشر بمهارات قرن

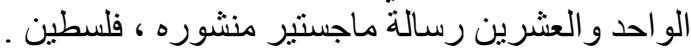

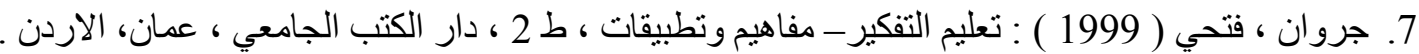

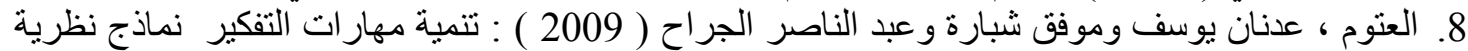

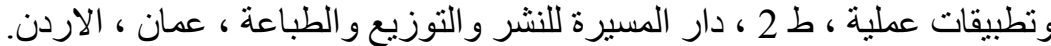

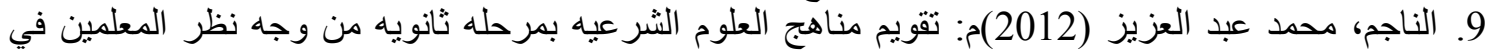

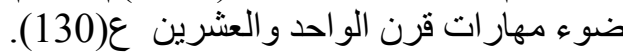

10. اليونسكو ، (1996): التعليم ذاكئ الكنز المدفون ، تقرير اللجنه التهن الدوليه المعنيه بالتربيه للقرن الحادي والعشرين

فرنسا مطابع اليونسكو.

11. (Watson, G.B. and Glasser, E.M(1991- Watson- Glasser Critical Thinking, Appraisal form, Harcourt Brace, Jovonovich publisher, London.

12. Hurson,T.(2008):Think Better. McGraw Hill ,United States.

13. Thinkx Intellectual Capital IP INC . (2012 ). Productive Thinking , Fundamentals Participant Workbook, Kanad . 